\section{Questión}

Periodismo / Comunicación ISSN 1669-6581
- Av. $44 \mathrm{~N}^{\circ} 676,1^{\circ}$ piso

CP 1900 - La Plata - Argentina

www.perio.unlp.edu.ar/question

Capítulo 15 / Amor Amarillo

Martín Marcos Martinic Magan

https://doi.org/10.24215/16696581e404

\title{
Capítulo 15 / Amor Amarillo
}

\section{Chapter 15 / Yellow Love}

Martín Marcos Martinic Magan

Docente, desde hace mucho: Periodista, aveces, Escritor, humanamente siempre. O la versión oficial: Docente de la Cátedra de Comunicación y Cultura nivel secundario y del Taller de Realización Audiovisual nivel terciario. Lic. en Comunicación Social-FPyCS.UNLP. Coordinador del Archivo de la Palabra-Radio

Provincia de Buenos Aires

Para Roldán, era el mejor de los tiempos. Habituado al aislamiento que confiere la eternidad. Era el peor de los tiempos, para Roldán. Ahora que había decidido camuflarse entre los mortales y sus ilusiones de perpetuidad. Las calles desiertas tenían una tristeza mágica. Era el tiempo de la sabiduría y de la locura. Persianas bajas y semáforos inútilmente persistentes. La época de todas las creencias y de cada incredulidad. La abundancia de cielo empequeñeciendo cada gesto de urbanidad. Era la primavera de la esperanza y el otoño de la desesperación. Todo estaba al alcance de unos pasos que nadie podía o quería dar. En una palabra, la era de la pandemia era un contraluz con el sol detrás de la mirada.

Gente vagando en silencio. Saludando a distancia con canchera displicencia. Pagando lo increíble por lo necesario. Añorando una normalidad que le había sido tan mezquina hasta la fractura del tiempo. La distancia, que en el pasado sólo estaba librada a los esclavos estigmatizados, ahora se democratizaba aun entre los premiados. Toda la meritocracia arrastrada a lo efímero. $Y$ los viajes como premio a la obediencia ahora reemplazados por recorridos introspectivos a la paz interior y el autoconocimiento. Las boludeces que surgieron al comienzo de la cuarentena, en donde cada une se prometió salir mejor, se desvanecieron cuando el mango empezó a menguar o, simplemente, a desaparecer. Y se agravó la miseria cuando los bancos mostraron su intacto desprecio y las cárceles tronaron de desesperación humana. 
Con el café cerrado, Roldán se entregó a la clausura, una vez más. Subió a facebook, diaria y militantemente, la foto de cualquier comida estrafalaria que sacó de google, con leyendas jactanciosas: "Esta noche toca Zarajo de Cuenca con papines andinos", ó "Con paciencia, disfrutamos de un Lutefisk delicioso y acorde a estos tiempos". Y bajo cada descripción culinaria, la infaltable cita: "no es comida sin sobremesa con Kopi luwak". Todo para que revienten de envidia los gorilas del laburo. Que ya ni me gusta le clavaban.

Comer, comer, de verdad, comía rico y tranquilo. Muchas verduras, pastas caceras y algún asadito frugal los domingos. Sabiendo que el Ruso estaría enclaustrado en la mansión. Con sus diarios sin edición impresa y sus Radios pasando música de emergencia. Toda su potencia dañina encarcelada en alcohol al $70 \%$ y lavandina para limpiar los vestigios del delivery. Una vez más, los emblemas de las dos Patrias en disputa eterna, confinados, latentes. Esperando que el coronavirus se cargue a seis millones de negros choriplaneros o que la eficacia solidaria de la cuarentena le amplíe la legitimidad a un gobierno humanista. Porque así de bestiales son las disputas en la Argentina. Así de lejos están los bordes del péndulo simbólico que mece la historia. De un lado, el Pueblo Argentino, devolviéndole al gobierno toda su dignidad. El aislamiento social preventivo es una epopeya, una gesta popular de solidaridad y comunión. Del otro lado, el cipayaje, moviendo los profundos hilos del poder para sostener la normalidad indigna, caiga quien caiga. Mientras sean pobres.

Pero la calma del equilibrio provisorio comenzó a estallar sordamente. Fue mas bien un resuello para que la oligarquía mediática embista con más fuerza en las asustadas mentes del universo receptivo. Como gotas de una tortura que sabe que el tiempo esta a favor de los verdugos, las operaciones de prensa desplegaron todos sus pertrechos: Supuestas médicas arengando a comprar todo el papel higiénico posible antes que venga lo peor; Falsas madres muertas sin la asistencia de respiradores; El default fatal con los bonistas internacionales; Espías Cubanos disfrazados de médicos; Campaña para que la política se baje los sueldos; Muertos escondidos en la morgue para exagerar la alentadora estadística oficial; La inflación danzando con el desabastecimiento; Un giro genial desde la irresponsabilidad de los chetos con fiebre viajando a Pinamar a la peligrosidad latente de los pobres hacinados en las villas sin agua. Y, como broche genial, la salida en manada de presos peligrosos para conformar grupos comandos comunistas. Definitivamente, el Ruso seguía operando. Ya no solo editoriales pulidas desde su escritorio, también la puesta en marcha del ejército de trolls agitando la maquinaria propagandística. Roldán 
no llegó a sorprenderse. Ya acostumbrado a las ventajas que saca la oligarquía en los instantes de tregua. Debía actuar con urgencia. Debía romper el protocolo al que se había incorporado, como siempre, como soldado de Perón. Debía volver al pasado para soñar el futuro.

Hizo la convocatoria por WhatsApp. Con el hermetismo que requería la odisea. Uno por uno. Pensando virtudes detalladamente. Eligiendo a cada integrante del nuevo viaje temporal con la dedicación de un Técnico al borde del descenso. Nacho y Mandinga, indiscutibles. Alguien picante por si las moscas. La lista era interminable, pero Alejandra se había ganado un lugar. Y un médico. Sanitarista, en lo posible. Peronista, obvio. Joaquín le agradeció, honrado por la convocatoria. Pero estaba hasta las manos en este presente de Ministerio de Salud devastado por el neoliberalismo y el seguimiento de la campaña de Boca Juniors en el 2002 que estaba reponiendo TyC Sports. La segunda opción también se cayó. Isidro estaba recién asumido en el Centro de Estudiantes de la Facultad de Medicina y los chinos se habían llevado las fotocopiadoras y vaciado el buffet. -Es un momento histórico para el peronismo universitario Roldán. Disculpe, pero no lo voy a poder acompañar, le escribió Isidro, entrada la noche, desde su despacho de cerveza, abierto solo para delivery. Matías también se sintió halagado. Pero, que el pibe es chiquitito, que la patrona, que necesitaba estar al pie del cañón por si el ministro lo precisaba, que la mar, que el coche. Tampoco se podía contar con él.

El tiempo se caía y no se le caía una sola idea. Tendría que partir con el equipo diezmado. Hizo un ultimo intento, tirando una convocatoria hiperencriptada en el selecto grupo de WhatsApp de peronistas indiscutibles, pero con destrezas dudosas y se aprontó al viaje con resignación realista y entusiasmo militante.

El grupo esperaba en la puerta de la cooperativa de diarios. Las manos muy metidas en los bolsillos. Zapateando el piso para saltar el frío. Los hilos de vapor ascendían desde los bordes de cada barbijo. Roldán llegó caminando. Dejó la Ford Ranger a unas cuadras para no avivar a la contra. Empezó a abrir los candados sin saludar a nadie. Cuando estaban por entrar asomó una prominente figura por la esquina de calle 2. Se paralizaron. El gigante avanzaba, en zigzag, pero determinado. Todo el devenir de la historia peronista estaba al borde, una vez más, de ser barrido del mapa como hecho maldito. Todos miraron a Roldán, desesperados. Tal vez por última vez. El coloso estaba a pocos metros. El silencio se cortaba como una fascia con un bisturí. El titán se detuvo, amenazante. Roldán se desprendió del grupo y lo encaró, entregado. El 357 latía 
muy lejos, en la sobaquera. El cíclope se plantó a centímetros de la jeta del viajero del tiempo. Silencio. Cristalizado silencio. Se bajó el barbijo y sonrió, ambiguo.

-Luquitas! ¡Qué hacés acá! ¿Buscando un after?, aventuró Roldán, tratando de entender, aliviado.

-Pedías un doctor... y vine, contestó con inocencia Lucas.

-Un médico, Lucas. Un Médico necesitamos.

-Bueno. Un abogado nunca viene mal. Además, estoy laburando en el Hospital El Cruce, en Varela. Administración. ¿Sirve?

Roldán sonrió, entre rendido y orgulloso. El peronismo siempre conmueve de entrega e intuición. -Dale, gordo. Calentá que entrás, dijo mientras irrumpía en la Cooperativa de diarios.

La metodología para viajar en el Tiempo era un secreto celoso y guardado bajo las mil llaves que servían de pliegues en la memoria de Roldán. Mandinga y Nacho, acostumbrados al proceso, esperaban tranquilos. Fumando cigarros conseguidos clandestinamente en medio del desabastecimiento o exagerando tamaños y cantidades ictícolas en salidas a paraísos de pesca. Alejandra repasaba nerviosa lo que había podido estudiar en la noche desvelada. Lucas aprovechó la espera para descabezar un sueño reparador.

Roldán, desempolvó los volúmenes de la hemeroteca secreta para organizar el dispositivo temporal.

- Revistas Para Ti y Gente (cantidad necesaria según humedad ambiente y presión atmosférica)

- 2 diarios El Día (del mes al que quiera llegar)

- 1 mensuario de Abuelas de Plaza de Mayo

- $\quad 1 / 2$ libro de Selecciones Readers Digest (Marzo de 1976)

- 1 diario Noticias (del día al que quiera viajar)

- 4 revistas de Actualidad Psicológica (pueden ser reemplazados por igual cantidad de Muy Interesante)

- 1 diario La Nación (del año al que se dirija/de ser necesario viajar a una fecha anterior a 1870 buscar en los estantes azules)

Con esos ingredientes de kiosco argento comenzaba Roldán la alquimia exacta para abrir lo que en literatura tradicional llamaríamos Portal espaciotemporal. Un zumbido grave, un sutil remolino de aire tibio, los ecos lejanos de la Marcha Peronista y... a 1871. 
Las callecitas de Buenos Aires tienen ese qué sé yo, de silencio lúgubre y atardecer amarillo como la peste. Acá y allá, sollozos apagados por la impotencia. En cada esquina de San Telmo encuentran una pira de colchones, muebles de inquilinato y ropa inmigrante. Mandinga manotea alguna camisa apenas chamuscada, alguna chalina, algún chambergo humeante. Nada le queda con la imagen de compadrito con la que fantasea, pero se adapta a la época en cuestión de minutos. Alejandra avanza conmovida. Lucas, resacoso. En el aire flotan nauseabundos olores a diarrea mezclados con carne quemada. El calor es demoníaco y la sequedad abrasa hasta los patios centrales de los conventillos.

-Recién empieza, dice Nacho, lúgubre.

-y faltan mas de setenta años para que asuma Carrillo, responde Roldán.

Avanzan los cinco buscando un fondín en donde instalarse. La tarea es ardua y el clima sobrecogedor.

Los acentos sicilianos, calabreses y lombardos se entrelazan en una tela semiótica que cubre el bajo cielo sobre la parra. Nacho ceba mates con yerba secada mientras Mandinga corretea a una checoslovaca demasiado joven como para dejarse alcanzar. Alejandra y Roldán andan por las callejuelas buscando sumar militantes para lo que vendrá. Lucas, indomable, es el encargado de buscar pertrechos e información jugosa.

-La viuda de Braga, está al horno. El presidente de la Comisión de Higiene la tiene montada en un huevo.

-Esa vieja mugrienta es un cachivache, que la chupe, responde Mandinga.

-Tenemos que estar atentos a las patotas que van a mandar los pitucos. Roldán tiene un plan, una estrategia y una táctica. Ninguno sabe bien, pero colaboran con intuición y solidaridad. El Ruso patrulla el sur de Buenos Aires en una diligencia color verde Falcon, erizada de carabinas. Les llegan rumores sobre fusilados en calles de Monserrat. Portadores. Portadores de cara, piel, origen o pobreza. El Pueblo esta aterrado frente a sus enemigos invisibles y los otros. Nacho empieza a pisar firme entre los inquilinos, el apellido lo ayuda, y Alejandra entre los referentes sociales. Poco se puede esperar del gobierno. Mucho menos de la aristocracia del barrio, que huye en manada a sus quintas del norte de la ciudad. Luquitas y Mandinga han desarrollado un trabajo de orfebrería entre las sirvientas. Las chamuyan cuando salen de compras para los patrones y hacen un laburo de inteligencia envidiable para cualquier organización política. Obtienen información, aconsejan, promueven desobediencias, seducen y rescatan. Cuando los 
ricachones escapan, con todo lo que pueden llevar en sus carruajes, el dúo ya está parapetado entre los árboles. Apenas la mudanza dobla la primera esquina se mandan. Abren las puertas cancel con la copia de las llaves que hicieron en alguna escapada entre besos y ayuda con las bolsas de compras. Entran a las habitaciones marcadas y saquean con elegancia y justicia. Las pibas, y los mulatos más avispados, los ayudan cargando botellas de licor inglés, pilchas pitucas, conservas españolas, cuadros de gusto dudoso y vajilla plateada. Después los siguen hasta el Hotel Roma, en donde Lucas cerró un acuerdo bastante digno con el encargado, y se instalan felices, abandonando a sus amos ya instalados en Belgrano, San Isidro o San Fernando. La vida en el Hotel es alborotada y difícil. El hambre y el miedo arrecian. Las piezas están colapsadas. A Lucas le cuesta encontrar un rinconcito para compartir lujuria con una tucumana que lo embrujó con su cintura de junco, sus ojos retintos y la cerrada noche de su pelo. Mandinga es menos delicado y pasa días sofocados amándose con italianas pulposas bajo la dudosa intimidad de las frazadas. La guita no les falta. Lucas encontró una solución práctica y expropiadora. A cada caserón abandonado por la oligarquía lo intervienen con tabiques improvisados y alquilan piezas pequeñas y altísimas por pocos pesos. Nacho se indigna un poco. Alejandra demasiado. Roldán casi no duerme. Ayuda a los médicos de día y patrulla de noche. El 357 tibio al costado del corazón y el pucho con boquilla como faro de las Almas en pena. Sueña con afán el cruzarse con el Ruso y su patota. Pero solo se cruza con la muerte. Ojos desorbitados por el miedo y el abandono. Bocas teñidas del aterrador vómito negro. Cuerpos amarillos, con carnes magras pegadas a los huesos. Apilados en las esquinas cerca de la vía recién construida. Cada mañana que se puede, los pocos voluntarios y las heroicas cuadrillas de laburantes municipales suben los restos pestilentes al tren de la muerte. Los conducen, hasta el cementerio de La Chacarita, desesperadamente inaugurado en esos días. Buenos Aires parece desaparecer ante la mirada vacía de los huérfanos.

-Acá tenemos que construir un Estado fuerte! Un Estado Peronista, clama Mandinga entre los pobres abandonados a su mala suerte.

-Estos pibes, son los abuelos de los que gestarán el 17 de Octubre, le susurra Alejandra. Metele mecha nomás... que algo queda.

Nacho arenga tratando de no anticipar el tiempo. Discute ese presente. Los ramales ingleses concentrándose en el puerto. El interior desangrado por unitarios y traidores. Los obreros sin organización sindical. El voto calificado. 
Mientras tanto, los diarios de Ruso taladran las mentes asustadas con estigmas sobre inmigrantes, gauchos y mulatos.

El Hotel Roma burbujea de pobrerío que se asoma a la historia. Calle Cangallo, entre Esmeralda y Maipú. Mandinga mira en cartel en la esquina y sonríe. -Sabés como se va a llamar esta calle? Le pregunta a una gallega hermosa que pugna por entrar. Ella se sonroja entendiendo un piropo. -Juan Domingo Perón, responde, cómplice con lo que vendrá. Abraza a la gallega y la ayuda a entrar entre apretujones picantes. Aparecen anarquistas y socialistas, a los que Lucas putea en colores. -Estos zurdos... siempre funcionales a la derecha, murmura. Los chicanea con anécdotas que nadie ha vivido aun y se pone pendenciero con la camisa empapada. El verbo se inflama, como se inflama la bronca. Las nubes negras cargan el aire de una tormenta que llega sobre mojado. Unos pocos, ven en Mitre una alternativa al "Loco", que la viene pifiando fiero. Y en eso, entra Roldán, a los gritos: ¡i¡Sarmiento se tomó el palo!!! ¡Rajó para Santa Fe! Con los ministros, los Jueces de la Corte y sus familias, detalla, agitado.

-de los jueces no me extraña nada, dice Alejandra. Pero nadie la escucha. Es momento de desesperación y de organizarse. Así, todo junto. Todo a la vez. Como casi cada vez que el Pueblo se siente acorralado y avanza.

Nacho organiza una votación en medio del caos. -Tenemos que armar una Comisión Popular de Salud Pública, esgrime, con tono de Asamblea. Algunos se prenden. Otros buscan profundizar la desesperación. Los más sacudidos por la epidemia se desmoronan sin esperanzas. -Eu! Eu! Si nos organizamos cogemos todos, dice Mandinga. Por suerte, en medio del quilombo, lo escucha solo Roldán, que agarra un carbón del bracero y empieza a dibujar en una pared blanca los resultados de la votación.

La lluvia es torrencial. Literal. Baja en torrentes por las calles anegadas. Arrastra, a su paso barroso hacia el bajo, muebles, maderaje, restos inciertos y cadáveres. Es semana santa. Es semana maldita. Quinientos muertos por día. Las morgues, los carros fúnebres, los médicos, las Almas no dan a vasto. Y como gota sangrienta rebasando el vaso de la injusticia, la policía cumple ordenes de desalojo en todos los conventillos. Las víctimas, como tantas otras veces, se han vuelto los acusados. La aristocracia profundiza su desprecio por los gauchos urbanizados y por los inmigrantes proletarios. Azuzan la psicosis colectiva en contra de españoles e italianos a través de los diarios del Ruso. 
-Igual que ahora, reflexiona Alejandra. A la peste la traen los oficiales chetos, volviendo de la guerra de la tiple alianza y ahora quieren tapiar las Villas.

-El gobierno porteño les pide higiene, suma Nacho. Pero los aguateros no vienen al Sur desde que empezó la epidemia.

Parece una confusión espaciotemporal. Una mezcla de épocas, de pestes, de actores... pero no. La Comisión de Salud organiza lo que puede hasta más allá de sus fuerzas. Junto a enfermeras, curas villeros y pocos médicos, palean el dolor de los infectados con solidaridad, quinina, evacuantes, palabras de despedida y revulsivos cutáneos. Cuando la fiebre avanza hasta devastar al raquítico ejercito sanitario, la Comisión saca un comunicado en donde, en síntesis, aconseja a los que puedan que huyan de Buenos Aires. La muerte ha triunfado.

El anochecer inunda la ciudad de sombras mudas y perros hambrientos. Los cinco viajeros avanzan por Bolívar, como espectros. lluminados por el fuego de piringundines incendiados. Los grupos de tareas del Ruso ejercitan las razzias que sostendrán en los tiempos grises de la Patria. El fuego fatuo bombardeando la dignidad de los humildes. Como un pulso de la historia. Llegando a la esquina de la calle Chile escuchan una explosión de vidrios y llantos rotos. Roldán les hace una seña sorda y se pegan a la pared de adobe. Avanzan agazapados. Conteniendo la respiración. Tensos, como pumas al acecho. Nacho se asoma por la ochava y vuelve, con sigilo. -Es una patota de pitucos, susurra. Andan con antorchas. Están... violando a una piba. Lucas empuja a Roldán, que intentaba armar una ronda para planear una táctica precisa. Va hasta la esquina y se planta en medio del empedrado. -qué onda, loco?!, grita. Empieza a avanzar hacia el centro de la jauría, sumida en el vejamen. Siete rubiecitos con trajes oscuros y chalecos de seda giran sorprendidos y abandonan el abuso. No pueden creer lo que ven. No solo por el tamaño de Lucas y su valentía, sino por encontrar a alguien que desafíe su impunidad de clase. Alguno dice algo, desde una sonrisa burlona y nerviosa. Lucas no escucha, ciego de furia. Mide al mas alto, que se acerca, blandito, como para hablar. Los puños como piedra. La panza como ariete. Calibrando el golpe. Y salta de atrás Mandinga y lo arrebata al lungo de una patada voladora y certera. Caen los dos. Mandinga se para como un resorte. El pituco no, Nunca Más. Lucas cambia de objetivo. Un pecoso quiere manotear algo de entre las pilchas. La trompada que lo desparrama es desprolija. Un poco hombro, un poco cuello, un poco nuca, y devastadora. La sangre mana de la oreja izquierda entre estertores. Nunca Más. La patota se congela de desconcierto. Llegan Roldán y Nacho al centro de la escena. Cinco contra cuatro. La cobardía 
contra la justicia. Los privilegiados de la colonia agroexportadora contra el subsuelo de la Patria sublevada. Nacho corre a un flaco de levita gris. En la esquina de Méjico las botitas le juegan una mala pasada. Resbala, se desacomoda, Nacho le cruza una patada que lo desestabiliza. Trastabilla en zancadas que lo aceleran. Y vuela, hasta reventar la cabeza contra un palenque. - No tocás a una compañera Nunca Más, oligarca del orto!, le escupe Nacho a la cara ensangrentada. Nunca Más.

Mientras tanto, Roldán está plantado al lado de la piba, que se acomoda las ropas como puede y mira la escena, odiando y celebrando. Los mira con calma. El fuego crece en el pórtico del conventillo. Sonríe, mientras Lucas tira piñas a discreción. Tres alcanzan a subir al carruaje. Tarde, distingue al Ruso, levantándose los pantalones mientras toma el látigo. De sus ropas, cae un aerosol familiar de repelente para mosquitos sin olor.

Fustigan a los caballos que se encabritan mientras huyen. El cuarto gime mirando el abandono desleal de sus secuaces. Corre hacia Bolívar con el rostro aterrado. Roldán se apresta, rodilla en tierra. Calculando mentalmente la velocidad del cobarde. Con la calma que tiene solo aquel que conoce los sabores del tiempo, mete su mano en la sobaquera y... el revólver no está. Cuando el rubito dobla la esquina, triunfal, se encuentra de frente con Alejandra. Inmóvil. Como una escultura de Lola Mora. Las piernas abiertas. Los brazos extendidos. Las manos empuñando el 357 con fiereza. Estalla la justicia. Nunca Más. 